\title{
Erratum
}

\section{S. D. BIJU, SONALI GARG, RACHUNLIU G. KAMEI \& GOPINATHAN MAHESWARAN (2019) A new Microhyla species (Anura: Microhylidae) from riparian evergreen forest in the eastern Himalayan state of Arunachal Pradesh, India. Zootaxa 4674: 100-116.}

In the originally published article the museum acronym and catalogue numbers for the type series of Microhyla eos were erroneously stated as ZSIC 14310 for the holotype and ZSIC 14311-14312 for the two paratypes. The updated museum acronym for the type series of Microhyla eos is ZSI (Zoological Survey of India, Kolkata), formerly ZSIC (Zoological Survey of India, Calcutta).”. The correct museum catalogue numbers for the type series of Microhyla eos are ZSI A 14397 for the holotype and ZSI A 14398-14399 for the two paratypes. It is also clarified that this correction only concerns the accession numbers of the types at ZSI and not their identity. The original description of Microhyla eos is based on correct specimens and stands valid as it is, except that the original text on the following pages should be read as:

On page 101, "Type specimens are deposited in Zoological Survey of India, Kolkata (ZSI), and referred specimens are available at Systematics Lab, University of Delhi (SDBDU).”

On page 102, "Molecular study. Total genomic DNA was extracted from a paratype (ZSI A 14399) tissue sample using Qiagen DNeasy blood and tissue kit (Qiagen, Valencia, CA, USA), following manufacturer’s protocol."

On page 103, TABLE 1., voucher number “ZSI A 14399” for M. eos sp. nov., item number 10 on row 13 of column 4.

On page 105, Abbreviations., "Zoological Survey of India, Kolkata (ZSI)”

On page 105, "Holotype. ZSI A 14397, an adult female from Rani Jheel (27³2’20.5" N, 96²9'17.6" E, 860 m asl), Namdapha National Park, Changlang district, Arunachal Pradesh state, India, collected by S. D. Biju, R. G. Kamei and G. Maheswaran, on 22 May 2011."

On page 105, "Paratypes. ZSI A 14398-14399, two adult females, collected along with the holotype."

On page 106, "FIGURE 2. Type specimens of Microhyla eos sp. nov. A, Paratype, ZSI A 14399, an adult female, dorsolateral view in life. B-K, Holotype, ZSI A 14397, an adult female: B, dorsal view in preservation; C, ventral view in preservation; D, lateral view in life; E, lateral view of head in preservation; F, ventral view of hand in preservation; $G$, third finger tip; $H$, ventral view of foot in preservation; I, schematic illustration of webbing on foot; J, fourth toe tip; K, terminal phalanx of fourth toe; L, Paratype, ZSI A 14399, an adult female, dorsolateral view in life. Scale bars: $5 \mathrm{~mm}$."

On page 107, "Morphological variations. Morphometric data from the type and referred specimens (male, $N=1$; females, $N=3$ ), including the holotype, is provided in Table 2.

The overall morphology of the paratypes is similar to the holotype with slight variations in colour and markings. ZSI A 14398 and ZSI A 14399: dorsal markings darker in colour; ZSI A 14398: ventral markings more prominent.”

On page 107, "Secondary sexual character. Female (ZSI A 14397): ova, pigmented on poles (diameter 1.0-1.6 mm, $N=10$ )."

On page 108, TABLE 2. "ZSI A 14397" "HT" on rows 2, 9, 16, and 23 of columns 1 and 2; "ZSI A 14398" "PT" on rows 3, 10, 17, and 24 of columns 1 and 2; and "ZSI A 14399" "PT" on rows 4, 11, 18, and 25 of columns 1 and 2.

On page 110, FIGURE 3., "Microhyla berdmorei, SDBDU 2018.3852, Barail, Assam, India; M. beilunensis, CIBA980059, Chaiqiao, Zhejiang Province, China; M. eos sp. nov., ZSI A 14399 (dorsolateral view) and ZSI A 14397 (lateral view), Rani Jheel, Arunachal Pradesh, India; M. mixtura, dorsolateral and dorsal views in life (voucher not preserved, China), dorsolateral view, CIB 65706, Wanyuan Country, Sichuan Province, China; M. pulchra, dorsolateral and dorsal views in life (voucher not preserved, China), dorsolateral view, CIB 68886, Yizhang, Hunan Province, China."

On page 111, "Distribution and natural history. Microhyla eos sp. nov. is currently known only from its type locality Rani Jheel in Namdapha National Park, Arunachal Pradesh, India (Fig. 1). ZSI A 14397 and ZSI A 14399 were collected from swampy forest floor on the fringes of a thickly vegetated lake located inside a tropical semi-evergreen forest patch. ZSI A 14398 and SDBDU 2011.380 were found under leaf litter away from water bodies." 